\title{
A IMPORTÂNCIA DO PROCESSO DE FORMAÇÃO DE EDUCADORES AMBIENTAIS NA EFETIVIDADE DO PROGRAMA NACIONAL DE ESCOLAS SUSTENTÁVEIS - PNES
}

Daniela Botti Dias Bastos ${ }^{1}$

Andréa Rabinovici²

Resumo: O Artigo é resultado de uma pesquisa de mestrado e objetiva evidenciar como a formação continuada de professores, articulada à formação de outros integrantes da comunidade escolar e local, pode potencializar a melhoria da prática pedagógica na implantação da Educação Ambiental formal dentro do programa Escolas Sustentáveis. Para tanto terá uma breve contextualização sobre Educação Ambiental (EA) e formação e sobre o histórico, as diretrizes propostas e ações que norteiam o Programa.

Palavras-chave: Educação Ambiental; Escolas Sustentáveis; Formação; Políticas Públicas;

1 Universidade Federal de São Carlos. E-mail: danielabastosconsultoria@yahoo.com.br

2 Universidade Federal de São Paulo. E-mail: andrearabinovici@gmail.com

Revbea, São Paulo, V. 11, № 4: 42-59, 2016. 


\section{Introdução}

Este artigo resulta da pesquisa de mestrado sobre a proposta de política pública para Escolas Sustentáveis (ES) no Brasil e procura focar nas implicações do processo de formação dos educadores ambientais na efetividade do Programa Nacional de Escolas Sustentáveis do Ministério da Educação (MEC).

O estudo estrutura-se, a partir de uma breve contextualização sobre educação e formação e sobre o Programa Nacional Escolas Sustentáveis e as diretrizes e propostas que o norteiam. Para tal, serão apresentadas breves explicações sobre as Conferências Nacionais Infanto-Juvenil pelo Meio Ambiente, e algumas reflexões sobre os conceitos de Escola Sustentável, os fundamentos dessa política e ponderação sobre a importância do processo de formação baseado no Programa - Escolas Sustentáveis e Com-Vida, Processos Formativos em Educação Ambiental, desenvolvido a partir de 2010, sob a coordenação da Secretaria de Educação Continuada, Alfabetização e Diversidade/MEC.

De acordo com Sato e Trajber (2010), o princípio fundamental da política para Escolas Sustentáveis é que as escolas de educação básica brasileira se transformem em "incubadoras de mudanças", onde deverão encontrar possíveis soluções para as dificuldades encontradas. A proposta busca, a partir de espaços educadores sustentáveis, incentivar a investigação, pesquisa, descoberta, autonomia, sonhos e possibilidades, assim como o pensamento crítico e inovador. É uma proposta criada para estimular a liberdade de escolhas, através da qual cada instituição decidirá com sua comunidade o melhor caminho em busca da sustentabilidade.

No Brasil, a Lei n. 9795, de 27 de abril de 1999, que dispõe sobre a EA e institui a Política Nacional de Educação Ambiental, iniciou um processo de inclusão da Educação Ambiental na formação inicial e continuada dos professores, além de estabelecer uma sequência de estudos para políticas públicas nesta área. Para Santos (2012) apesar da diversidade de modalidades e estratégias nota-se que, de um modo geral, os cursos estão focados na formação teórica e/ou prática desses profissionais para atuação na escola, trazendo pouca articulação com outros elementos necessários à consecução da sustentabilidade ambiental dentro e fora do ambiente escolar.

Os esforços de implementação das Políticas Públicas relacionadas à referida lei e ao Plano Nacional de Educação Sustentável, desdobramento formalizado desse processo, não se verificaram na prática, pelo menos até o final desta pesquisa. $O$ que se percebeu foi a existência de tentativas pulverizadas de efetivação do projeto.

Santos (2012) vislumbra a necessidade da coerência entre o currículo, a gestão e o espaço físico para a consecução da sustentabilidade ambiental provocada pela escola. E, consequentemente formação de professores que contemple essa perspectiva.

Revbea, São Paulo, V. 11, № 4: 42-59, 2016.

revista brasileira

educação ambiental 
Nesse contexto, o presente estudo objetiva evidenciar como o processo de formação envolvendo docentes, gestores e outros integrantes da comunidade escolar e local pode contribuir para o cumprimento dos objetivos do Programa Nacional Escolas Sustentáveis (PNES).

$\mathrm{Na}$ análise do documento "Educação Ambiental: aprendizes de sustentabilidade" (BRASIL, 2007), o programa "Vamos Cuidar do Brasil com as Escolas" prevê quatro ações estruturantes: a) Conferência Nacional InfantoJuvenil pelo Meio Ambiente; b) Formação continuada de professores e estudantes; c) Inclusão digital com Ciência de Pés no Chão; d) Ações Estruturantes: Com-Vidas, Coletivos Jovens de Meio Ambiente e Educação de Chico Mendes.

Entre estas quatro ações do programa "Vamos Cuidar do Brasil com as Escolas", este estudo se baseou na Conferência Nacional Infanto-Juvenil pelo Meio Ambiente, para explicar o processo que teve uma ampla repercussão no país em 2013, estimulando a participação das escolas na elaboração de projetos de Educação Ambiental e de onde partiu o programa em si e principalmente no item dos processos de Formação, objeto desta discussão.

A análise do curso de formação emerge das leituras dos materiais pedagógicos, relatórios, depoimentos dos participantes do processo formativo e entrevistas com especialistas com ligação direta ao Programa, em sua elaboração e aplicação.

\section{Educação Ambiental e formação}

Para Machado (2008) a maneira como a EA é desenvolvida nas escolas pouco contribui para que elas possam se constituir enquanto espaço educador sustentável. Esta EA fomenta ações pontuais, fragmentadas e isoladas, deixando a impressão de que alguma coisa está sendo feita, ao mesmo tempo em que não permite que a temática ambiental seja devidamente incluída no currículo escolar. Segundo a autora:

As dificuldades específicas no desenvolvimento das atividades em EA referem-se à formação inicial e continuada dos professores, à falta de tempo e de espaço adequado para reuniões de planejamento, estudo e pesquisa, individual e/ou coletivo, à escassez e até inexistência de recursos materiais e repertório metodológico e, por fim, à dificuldade na organização do currículo escolar, constituído por uma estrutura disciplinar, linear e fechada (MACHADO, 2008, p. 60). 
práticas socialmente construídas pelas antigas e atuais gerações, incluindo, nestas últimas, os sujeitos que constituem a unidade escolar e seu entorno.

Para Wiziack, Vargas e Zanon (2013), muitas vezes a concepção de EA recente é desprovida de crítica. Este é um dos obstáculos presentes no processo de formação, o que leva a enfatizar a importância da formação de professores e também refletir sobre a concepção de ambiente e de EA que se deseja trabalhar.

Para Santos (2012) a formação continuada de professores em EA é vista não apenas como complementar à formação inicial, mas como parte de um processo necessário e indispensável à função docente de saber ensinar, ou seja, saber fazer o outro aprender, proporcionando-lhe domínio de conhecimentos, valores, habilidades e aprendizagens que possibilitem entender e transformar o mundo.

Processos formativos em EA precisam ocorrer dentro da escola, no cotidiano escolar de maneira permanente e contínua, envolvendo todos os setores: direção, professores, funcionários, estudantes pais e comunidade do entorno.

Segundo Sorrentino e colaboradores (2005), o MEC e o Ministério do Meio Ambiente (MMA), passaram a atuar junto aos seus públicos específicos dentro de uma perspectiva crítica, popular e emancipatória, almejando desvelar processos continuados e articulados com processos transformadores a partir de uma visão sistêmica e permanente do processo educacional, em detrimento de cursos pontuais ou de um ativismo vazio (SORRENTINO et al., 2005).

A abordagem em EA, a partir das diretrizes do Plano Nacional de Educação Ambiental, no que tange a formação de Educadores não se limitava mais a conceitos ecológicos e sim mais próximos da realidade, incluindo fatores físicos, biológicos e socioeconômicos. A responsabilidade na elaboração desses cursos já não era vertical, imposta pelo MEC, e sim mais participativa e com foco em promover uma nova racionalidade. Os processos tinham continuidade e aplicavam-se diretamente à realidade dos educadores.

Muitas Secretarias Estaduais de Educação e até municipais (principalmente os grandes municípios) também realizaram ações de formação de professores, além daquelas realizadas por Organizações Não Governamentais (ONGs) e empresas. Segundo Sotero (2010), essas ações não estão integradas, conectadas e podem desta forma, contribuir para a soma de esforços evitando o desperdício de recursos públicos. Segundo o autor é urgente a busca por sinergia, articulação e conexão entre os diversos envolvidos no campo da EA, seja no próprio Estado - entre poderes, entes e instituições - seja na sociedade. A falta de articulação entre esses poderes é possivelmente o grande gargalo para a implementação efetiva da PNEA. 


\section{Espaço Educador sustentável e Escolas Sustentáveis}

Segundo Moreira (2011), espaços educadores sustentáveis são aqueles que desenvolvem processos educativos permanentes e continuados, capazes de sensibilizar a comunidade escolar para a construção de uma sociedade de direitos, ambientalmente justa e sustentável, por meio de três dimensões interdependentes: currículo, gestão e espaço físico.

$\mathrm{Na}$ escola, por meio de profissionais preparados e comprometidos, os estudantes poderão ser esclarecidos e sensibilizados para desenvolver práticas ambientalmente corretas (SATO; CARVALHO, 2005). Nesse aspecto é imprescindível que a escola, como espaço de transformação social, crie oportunidades ao aprendiz de desenvolver conhecimentos no campo da ecologia, do meio ambiente e questões derivadas, a partir de ações pedagógicas individuais e coletivas (DIAS, 2004).

A definição de Escolas sustentáveis, de acordo com o Manual Escolas Sustentáveis (Resolução FNDE N 18 de 21 de maio de 2013), é:

Escolas sustentáveis são definidas como aquelas que mantêm relação equilibrada com o meio ambiente e compensam seus impactos com o desenvolvimento de tecnologias apropriadas, de modo a garantir qualidade de vida às presentes e futuras gerações. Esses espaços têm a intencionalidade de educar pelo exemplo e irradiar sua influência para as comunidades nas quais se situam. A transição para a sustentabilidade nas escolas é promovida a partir de três dimensões interrelacionadas: espaço físico, gestão e currículo (BRASIL, 2013, $\mathrm{s} / \mathrm{p})$.

No que diz respeito aos caminhos necessários para construção dos espaços educadores sustentáveis, o documento "Vamos Cuidar do Brasil com Escolas Sustentáveis" (BRASIL, 2012) fala sobre os eixos de atuação, onde se propõe articular currículo, espaço físico e gestão nas instituições de ensino.

$\mathrm{Na}$ escola sustentável, o espaço físico cuida e educa, pois incorpora tecnologias e materiais mais adaptados às características ambientais e sociais de cada região. (...) $\mathrm{Na}$ escola sustentável, a gestão cuida e educa, pois encoraja relações de respeito à diversidade, mais democráticas e participativas. O coletivo escolar constrói mecanismos eficazes para a tomada de decisões por meio da Comissão de Meio Ambiente e Qualidade de Vida. (...) Na escola sustentável, o currículo cuida e educa, pois é iluminado por um Projeto PolíticoPedagógico que estimula a visão complexa da educação integral e sustentável (BRASIL, 2010. p.11). 
Em 2012, para fortalecer a implementação do Programa, foi assinada pelos ministros de Estado da Educação e ministra de Estado do Meio Ambiente a Portaria Interministerial $\mathrm{n}^{\circ}$ 883, de 5 de julho de 2012. Esta tem como objetivos:

Propiciar atitude responsável e comprometida da comunidade escolar com as questões socioambientais locais e globais, com ênfase na participação social e nos processos de melhoria da relação ensino aprendizagem, em uma visão de educação para a sustentabilidade e o respeito à diversidade de modo a: Fortalecer a Educação Ambiental nos sistemas de ensino; Fortalecer a participação da comunidade escolar na construção de políticas públicas de educação e de meio ambiente; Apoiar as escolas na transição para a sustentabilidade, contribuindo para que se constituam em espaços educadores sustentáveis a partir da articulação de três eixos: gestão, currículo e espaço físico; Estimular a inclusão de propostas de sustentabilidade socioambiental no Projeto Político Pedagógico (PPP) a partir da gestão, currículo e espaço físico; Fortalecer a participação da juventude na implementação da Política Nacional de Educação Ambiental e incentivá - la a contribuir com a solução dos problemas socioambientais (BRASIL, 2012, p. 194).

Santos (2012) ressalta que a lógica da cooperação, do reconhecimento da realidade local com suas fragilidades e potencialidades assim como o trabalho voltado a intervenções de melhoria da escola é o diferencial para reconhecer que a prática pedagógica envolvendo EA não se faz isoladamente, mas em conjunto com o coletivo da escola.

Para construir uma escola sustentável é necessário, no contexto atual, reinventá-la, propondo uma experiência que possa ressignificar as formas de entender como os sujeitos percebem a importância das questões ambientais e seus desdobramentos. Essa ressignificação deve acontecer de tal forma que, de fato, as experiências sejam transformadoras de atitudes e comportamentos.

Em uma breve pesquisa derivada deste estudo, realizada em páginas da internet, é possível verificar diversos casos pontuais de escolas sustentáveis, com projetos que evoluíram de forma satisfatória, outros que acabam interrompidos no processo. Muitas vezes, algumas ações simples propiciam a possibilidade de a escola rever algumas práticas, já no curso de transformação delas.

O processo a ser perseguido é longo, mas já se iniciou. Durante as jornadas e mesas redondas do VIII Fórum Brasileiro de Educação Ambiental (FBEA), foram abordados casos de sucesso na implantação. Porém, esta pesquisa não obteve resultados quando consultou o MEC. Não há informações disponíveis sobre o resultado do projeto das escolas contempladas e, escolas

Revbea, São Paulo, V. 11, № 4: 42-59, 2016.

revista brasileira educação ambiental 
que receberam recursos financeiros muitas vezes não o utilizaram ou não prestaram contas de seu uso. Considerando que a primeira distribuição de recursos se deu em 2013, verifica-se que a avaliação fica completamente prejudicada.

São muitos os elementos necessários para a consolidação de uma escola sustentável. Fatores que envolvem recursos, desde financeiros à adaptação de espaços físicos, conhecimento aprofundado para uma modificação de currículo. Neste último quesito, é preciso ressaltar que, além de seguir diretrizes obrigatórias, existem outras demandas, muitas vezes associadas ao tempo para os gestores elaborarem um projeto-político pedagógico, o que, muitas vezes, pode inviabilizar sua conclusão, e ainda, todos os fatores ligados à gestão, os quais envolvem não somente o ambiente escolar, como a comunidade e seus paradigmas culturais, necessidade de participação, engajamento e muitas vezes mudança de valores.

Considerando o dinamismo das transformações que cercam esta temática, pode-se perceber o quão necessário se faz possuir uma política pública que acompanhe e faça gestão e avaliação destas movimentações, além de estar sempre em consonância com as demandas apresentadas.

\section{CNIJMA}

Entre 2003 e 2013, os Ministérios da Educação e do Meio Ambiente incentivaram a juventude brasileira a participar das decisões políticas relacionadas à $\mathrm{EA}$, por meio do coletivo jovem Com-Vidas, que se reúne tendo como prerrogativa a participação nas Conferências Nacionais Infanto-Juvenis pelo Meio Ambiente (CNIJMA) as quais têm como condição de participação a apresentação de projetos, avaliados em âmbito estadual e selecionados para o evento federal.

A primeira Conferência Nacional Infanto-Juvenil pelo Meio Ambiente ocorreu no ano de 2003, envolvendo 15.452 escolas mobilizando 5.658.877 pessoas, em 3.461 municípios em todo o país. Em 2005, a segunda conferência envolveu 11.475 escolas, 3.801.055 pessoas em 2.865 municípios. A terceira, no ano de 2009, atingiu o número de 11.631 escolas, mais de 3,7 milhões em 2.828 municípios brasileiros (MEC, MMA, 2012). O objetivo geral destas conferências foi o de fortalecer a Educação Ambiental nos sistemas de ensino, fomentando espaços de participação de jovens estudantes na elaboração de propostas e projetos ambientais.

Ao comparar as conferências, verifica-se que o número de participantes foi reduzido de um ano a outro. Fato se deveu à limitação imposta pelo MEC de número de participantes, bem como a utilização do critério de proporção de escolas por estado.

As exigências para participação foram aumentando no decorrer das Conferências, e na última, o critério exigido no regulamento foi a análise dos projetos das escolas, selecionados nas conferências estaduais. 
A última Conferência Nacional Infanto Juvenil pelo Meio Ambiente, em 2013, envolveu muitos jovens de diversos estados e municípios. Segundo José Vicente de Freitas, Coordenador Geral de Educação Ambiental do Ministério da Educação, em entrevista, a IV CNIJMA contou com a participação de quase 20 mil escolas". O tema desta conferência foi "Vamos Cuidar do Brasil com Escolas Sustentáveis". O livreto referente a esta conferência retoma o conceito de Escola Sustentável, referindo-se a ela como um local onde se desenvolvem processos educativos permanentes e continuados, capazes de sensibilizar o indivíduo e a coletividade para a construção de conhecimentos, valores, habilidades, atitudes e competências voltadas para a construção de uma sociedade de direitos, ambientalmente justa e sustentável (BRASIL, 2012). Cada estado teve um número expressivo de escolas participantes, sendo que na primeira etapa (conferências nas escolas), 16.538 enviaram seus projetos, segundo dados do MEC.

A união de coletivos na elaboração desses projetos, trazendo a EA para a realidade escolar e comunidade, aproxima e engaja os estudantes a deixarem a teoria e tentarem aplicar, dentro das limitações, efetivas mudanças na escola e entorno. O envolvimento de todo o corpo escolar (administração, docentes, discentes e comunidade) fortalece a ideia de pertencimento e estimula sua realização quando podem perceber a viabilidade desses projetos se efetivarem e trazerem melhorias.

\section{Programa Nacional Escolas Sustentáveis}

Logo após a IV CNIJMA, o primeiro semestre do ano de 2014 ficou marcado pela divulgação de documentos sobre o Programa Nacional Escolas Sustentáveis. A versão preliminar do Programa, apresentada pelo MEC (datada de 20 de maio de 2014), aponta que o documento foi construído a partir de aportes fornecidos por atores sociais, incluindo profissionais da educação formal de todos os níveis e modalidades de ensino do País, e, mais especificamente, de educadores e educadoras ambientais, membros de coletivos como as redes, que participaram de eventos realizados pelo MEC durante 2013, entre eles, a própria IV CNIJMA. Neste processo de construção do Programa Nacional Escolas Sustentáveis, somaram-se ainda, profissionais dos Ministérios do Meio Ambiente, da Ciência, Tecnologia e Inovação e da Integração Nacional.

O Programa Escolas Sustentáveis foi uma inspiração de uma proposta inglesa, mas que teve diversas alterações, desconstruções e construções sob a coordenação da Coordenadoria Geral de Educação Ambiental (CGEA) do MEC e três universidades federais que colaboram na transformação da proposta: Mato Grosso (UFMT), Mato Grosso do Sul (UFMS) e Ouro Preto (UFOP). O

${ }^{3}$ Entrevista disponível em <http://www.portaldomeioambiente.org.br/educacao-ambiental/8541-resultadosda-iv-conferencia-nacional-infanto-juvenil-pelo-meio-ambiente-iv-cnijma> consulta em 14 dez 2014.

Revbea, São Paulo, V. 11, № 4: 42-59, 2016.

revista brasileira educação ambiental 
lançamento do programa ocorreu em 2010, no SESC Pantanal, em Poconé, MT.

A proposta do Programa Escolas Sustentáveis encontra-se em consonância com o Programa Nacional de Mudança do Clima (PNMC), que propõe a "[...] implementação de programas de espaços educadores sustentáveis com readequação de prédios (escolares e universitários) e da gestão, além da formação de professores e da inserção da temática mudança do clima nos currículos e materiais didáticos" (BRASIL, 2008, s/p).

O Programa Nacional Escolas Sustentáveis não se consolidou como um Programa. Segundo informações concedidas através da entrevista de Rachel Trajber $^{4}$, por conta da falta de prioridade do Governo tanto em educação, como $E A$, os recursos foram pulverizados, insuficientes e não foi possível analisar os casos de forma a fazer uma avaliação completa de sua aplicabilidade e eficiência.

Para sua implantação, surge o Programa Dinheiro Direto na Escola (PDDE), como uma linha de ação específica para Escolas Sustentáveis, de forma a distribuir recursos a escolas que apresentassem projetos de modificação de um dos eixos (espaço físico, gestão ou currículo).

\section{PDDE - ES}

O PDDE voltado às Escolas Sustentáveis é uma das ações do PNES e, de acordo com a Resolução FNDE $n^{\circ} 18$ de 21 de maio de 2013 que o regulamentou, tem como objetivo promover a assistência financeira, por meio de transferência de recursos de custeio e de capital, para os projetos nas escolas, preconizando adoção de critérios do programa, de forma a tornar a escola um espaço educador sustentável.

É importante esclarecer que nessa primeira edição do PDDE-ES um dos critérios de priorização das escolas era encontrar-se em município de eminência de situação de risco ambiental, ter participado das CNIJMA e ter participado dos processos formativos fomentados pelo MEC. Tais critérios foram estabelecidos como forma de incentivar, com recursos financeiros, as escolas que já realizam ações voltadas à Educação Ambiental.

Cabe ressaltar a importância do processo formativo como critério com intenção de instruir os educadores, ampliando seu direcionamento, e promover uma aplicabilidade dos recursos mais efetiva e eficaz dentro dos objetivos de consolidar espaços educadores sustentáveis. Em uma situação cuja equipe gestora não possui conhecimentos aprofundados para elaborar um novo projeto político pedagógico seguindo as premissas da sustentabilidade, o processo de formação torna-se essencial.

${ }^{4}$ Entrevista realizada em: 22/02/2016. Entrevistadora: Daniela Botti Dias Bastos.

Revbea, São Paulo, V. 11, No 4: 42-59, 2016. 
Destacamos os valores indicados no manual PDDE (Tabela 1):

Tabela 1: Valores do Programa Dinheiro Direto na Escola, PDDE - Escolas Sustentáveis.

\begin{tabular}{|l|r|r|r|}
\hline \multirow{2}{*}{ Número de alunos } & \multicolumn{3}{|c|}{ Valores de Repasse (R\$) } \\
\cline { 2 - 4 } & Custeio (80\%) & Capital (20\%) & \multicolumn{1}{c|}{ Total } \\
\hline Até 199 & $6.400,00$ & $1.600,00$ & $8.000,00$ \\
\hline 200 a 499 & $8.000,00$ & $2.000,00$ & $10.000,00$ \\
\hline 500 a 999 & $9.600,00$ & $2.400,00$ & $12.000,00$ \\
\hline Acima de 999 & $11.200,00$ & $2.800,00$ & $14.000,00$ \\
\hline
\end{tabular}

Fonte: Manual Escolas Sustentáveis (SECADI/MEC, 2013).

A $2^{\text {a }}$ edição do PDDE-ES através da Resolução FNDE no 18/2014 teve como condicionante (e não mais priorização) a realização IV edição da CNIJMA, com os projetos elaborados pelas escolas e ter cadastrado essa realização no site da Conferência. Os eixos e valores por escola e número de alunos foram mantidos. Nesta edição a formação não foi um critério de priorização. Outra alteração em 2014 após discussões com especialistas, foi a inclusão de uma nova dimensão para a Escola Sustentável, além de Currículo, Gestão e espaço físico, acrescenta-se a escola-comunidade.

Diante do quadro apresentado, é possível perceber que os recursos previstos para as escolas públicas são reduzidos, tendo em vista os desafios do Programa. Outro aspecto a ser considerado é o espaço físico escolar. Em muitas escolas estes espaços vêm de um histórico de deterioração, seja por má gestão, ou por falta de manutenção. Ou seja, o recurso destinado a tornar o local sustentável, acaba por ser aplicado em situações necessárias a cada escola.

A seguir, algumas informações sobre as ações passíveis de financiamento nas escolas, segundo dados obtidos no mesmo Manual:

1. Apoiar a criação e o fortalecimento da Comissão de Meio Ambiente e Qualidade de Vida na Escola (COM-VIDA). 2. Adequar o espaço físico, visando à destinação apropriada de resíduos da escola, eficiência energética e uso racional da água, conforto térmico e acústico, mobilidade sustentável e estruturação de áreas verdes. 3. Promover a inclusão da temática socioambiental no projeto político-pedagógico da escola (BRASIL, 2013, s/p). 


\section{O processo formativo Educação Ambiental: Escolas Sustentáveis e Com-Vida}

A proposta de formação no Programa Escolas Sustentáveis teve como ação estruturante o Edital de № 06 da SECADI/MEC, de 1ํ de abril de 2009. Seu objetivo era convocar Instituições Públicas de Ensino Superior, integrantes do Sistema Universidade Aberta do Brasil (UAB) e respectivos núcleos de pesquisa para proporem cursos de formação continuada à distância nas modalidades de extensão, aperfeiçoamento e especialização. Esses cursos seriam ofertados nos polos de apoio presencial da UAB aos professores das redes de ensino público da educação básica no Brasil (BRASIL, 2009). O edital mencionava que os proponentes poderiam apresentar propostas de cursos com temas variados, entre eles: o Curso de Educação Ambiental - escolas sustentáveis e Com-Vida, com carga-horária de 90h. Foi assim que três universidades públicas - Universidade Federal de Ouro Preto (UFOP), Universidade Federal do Mato Grosso (UFMT) e Universidade Federal do Mato Grosso do Sul (UFMS) - associaram-se em um projeto de extensão, por meio do sistema UAB para ofertar o curso para professores sobre Escolas Sustentáveis.

A primeira versão do curso foi intitulada "Processo Formativo em Educação Ambiental Escolas Sustentáveis e Com-Vida", ocorreu no ano 2010 e foi concebido para a formação de professores do ensino fundamental e médio. $O$ curso foi estruturado para atender às demandas para formação continuada de professores. Como resultado deste curso, identificou-se que o mesmo foi oferecido em 16 estados e no Distrito Federal, abrigando cerca de 1.600 cursistas, inscritos em 39 pólos da Universidade Aberta do Brasil (PEREIRA; MENDONÇA; SOUZA; ZANON, 2011).

Em 2011 a Rede mudou de nome para "Rede Nacional de Formação Continuada dos Profissionais do Magistério da Educação Básica Pública", instituída pela Portaria Ministerial no 1.328 , de 23/09/2011, no âmbito da Política Nacional de Formação de Profissionais do Magistério da Educação Básica - Decreto no 6.755, de 29/01/2009. Para efetivar os cursos de educação a distância, a UAB firmou uma parceria com a CAPES, que foi essencial a esse projeto.

Segundo Santos (2012) a concepção do curso e do material pedagógico ocorreu de forma cooperada entre as universidades e a CGEA/MEC. Essa decisão visou criar a identidade do processo formativo e otimizar as particularidades de cada IES na consecução dos objetivos propostos.

O programa se vinculou a três pressupostos pedagógicos: cuidado, integridade e diálogo (BRASIL, 2012, p.11):

1. Cuidado: considera o sujeito historicamente situado, consciente de sua existência, seus sonhos, valores e sentimentos, porém entrelaçado no marco de um projeto coletivo da humanidade.

Revbea, São Paulo, V. 11, № 4: 42-59, 2016. 
2. Integridade: capacidade de exercitar a visão complexa e vivenciar o sistema educativo desenvolvendo uma práxis coerente, entre o que se diz e o que se faz. Um espaço que proponha o enraizamento dos conceitos trabalhados na ação cotidiana.

3. Diálogo: exercício constante de respeitar as diversas referências, acadêmicas ou populares, os valores de cada biorregião, e a capacidade de transformar a escola como um espaço republicano, a coisa pública, de todos e todas, de aprendizagem ao longo da vida e de democracia.

Wiziack, Vargas e Zanon (2013) relatam que:

O processo formativo se inicia com a memória ambiental de cada cursista. Dessa forma, o primeiro módulo denomina-se "EU", sendo nele realizado o registro da biografia ecológica e pegada ecológica individual. $O$ intuito é o da construção de uma ecoidentidade, ou de uma identidade desse educador ambiental. No segundo módulo, o "OUTRO" é abordado. Com ele, a escola surge como referência para a construção do que se denomina co-responsabilidade. Nesse momento, o cursista se envolve diretamente com a sua escola, buscando compreendê-la em sua amplitude socioambiental. São focados elementos da gestão, do currículo e do espaço da escola. Também são incentivados diálogos que permitam entender e rever o Projeto Pedagógico Os cursistas elaboram um mapa da escola em sua relação com a comunidade. O terceiro módulo o "MUNDO", chamando a atenção para a comunidade, sem perder a referência da escola. A idéia é que neste momento os cursistas possam fortalecer escola e comunidade para influírem nas políticas locais em favor da sustentabilidade socioambiental. A proposta culmina com um projeto de escola considerando-a um espaço educador sustentável. Pressupõe repensar o ambiente, no sentido de torná-lo integrador, educador e sustentável, implica sua adequação em termos arquitetônicos, isto é, redesenhar os espaços de acordo com novas finalidades (WIZIACK; VARGAS; ZANON, 2013, p. 3-4).

Os cursistas são motivados ao exercício de pensar e implantar ações sustentáveis, inclusive práticas ecológicas (TRAJBER; SATO, 2010).

Para Machado (2008), a tendência na escola é não conectar as diversas ações individuais que ocorrem no seu espaço. Cria assim, ações soltas e frustrantes para aqueles que a desenvolvem e que, dificilmente, conseguem dar continuidade. 
No contexto escolar, muitas vezes a EA acaba por ser limitadamente abordada por professores de Ciências/Biologia e eventualmente Geografia. O Programa procura incentivar a participação de docentes de outras disciplinas, bem como Coordenadores pedagógicos e funcionários, de forma a aumentar o envolvimento destes no processo participativo, segundo Moreira (2016)

A tendência na escola é não conectar as diversas ações individuais que ocorrem no seu espaço. Cria assim, ações soltas e frustrantes para aqueles que a desenvolvem e que dificilmente conseguem dar continuidade.

O empenho no trabalho coletivo, na organização dos membros da comunidade escolar, especialmente com o estímulo a revisita ao Projeto Político Pedagógico (PPP), evidencia a preocupação de que na formação o educador ambiental perceba a potencialidade desse projeto como uma ação democrática e participativa, uma importante ferramenta política de inserção da Educação Ambiental na escola (WIZIACK; VARGAS; ZANON, 2013).

O potencial do PPP incide no fato de se tornar um lócus para a Educação Ambiental escolar. Se construído de forma legítima, como um processo democrático constitui um meio para quebrar relações de poder, inclusive na construção do currículo escolar. Dessa forma, a inserção da EA, entendida em seus princípios libertários, confere a autenticidade necessária para rever questões fundamentais da gestão, do ensino e do currículo escolar, permitindo que a escola institua significações capazes de rever valores presentes entre os membros da comunidade escolar (WIZIACK, 2006). Enfim, o curso:

Promoveu vivências concretas de sustentabilidade no espaço escolar, com integridade de conceitos e práticas. Mostrou que é possível transformar hábitos e a lógica de funcionamento, reduzir impactos ambientais e indicar uma referência de vida saudável para sua comunidade, ampliando seu escopo de ação para além das salas de aula, apoiada em políticas públicas e Educação Ambiental (PEREIRA; MENDONÇA; SOUZA; ZANON, 2011, p. 6)

Para Machado (2008) não será o "esverdeamento" do espaço escolar que o tornará mais educador ou mais sustentável. Não basta a escola colocar latões de reciclagem no pátio, fazer uma pequena horta e comemorações pontuais como o dia da água. O currículo escolar, na maneira como vem sendo concebido, ao invés de superar a crise socioambiental, produz e reproduz a impossibilidade de compreendê-la em sua totalidade, resultando, portanto, numa pedagogia redundante (GUIMARÃES, 2003).

Kassiadou e Sánchez (2014) em análise de projetos das escolas de três municípios do Rio de Janeiro, puderam perceber que existe um predomínio de

${ }^{5}$ Entrevista realizada em: 16 /02/ 2016. Entrevistadora: Daniela Botti Dias Bastos.

Revbea, São Paulo, V. 11, № 4: 42-59, 2016. 
projetos que focam em questões socioambientais mais genéricas, fundamentadas talvez, em um senso comum sobre questões relativas ao campo da EA e que parece não estar percebendo a realidade socioambiental do território, onde estão situadas as escolas. E ainda, defendem a incorporação das dimensões pedagógicas dos conflitos ambientais, tanto nos projetos de EA, quanto nas diretrizes das orientações para a elaboração dos projetos, de maneira que possam servir como subsídios nas práticas cotidianas escolares e nas políticas públicas do campo.

Wiziack, Vargas e Zanon (2013) por fazerem parte dos grupos docentes envolvidos no processo de formação, apontam que, a despeito da tendência dominante de limitar um único modelo de formação de professores com o intuito de preparar os professores e de capacitá-los para a execução de habilidades, se coloca como proposta de reflexão sobre a ação dos profissionais da educação, ou seja, num caminho de aproximação daquilo que o pesquisador denomina de movimento de reflexão sobre a ação, que tem potencialidade para desempenhar papéis mais ativos dos profissionais da educação.

O processo formativo "Escolas Sustentáveis e Com - Vida" foi identificado por Grohe (2012) como essencial para o fortalecimento da política para Escolas sustentáveis. No entanto esta formação não está presente em todos os estados do Brasil. No ano de 2014, apenas os estados de Alagoas, Amapá, Bahia, Espírito Santo, Minas Gerais, Pará, Rio de Janeiro e São Paulo, aderiram. Número muito significativo, mas ainda pouco, se relacionado ao número de estados brasileiros.

Ainda em 2014 foram aprovados projetos para oferta do curso de Extensão ESCV pelas seguintes Instituições de Ensino Superior (IES): UFC, UNB, UFV, UFOP, UFMS, UFPA, UFRA, UFCG, UFPE, UFPI, UFPR, UFF e UFSM. Em algumas IES, o curso teve início em 2015 e em outras o MEC aguarda decisão da IES para saber se serão ou não ofertados em 2015, após confirmação do orçamento.

\section{Considerações finais}

O PNES não chegou a se institucionalizar plenamente. Sorrentino ${ }^{6}$, em entrevista, menciona "a falta de apoio efetivo de toda a estrutura do MEC para que seja implantado com recursos, continuidade e de forma articulada junto às quase 200 mil escolas do país e, tivesse sua permanência garantida, com uma dotação orçamentária que garantisse sua continuidade". O entrevistado também menciona que "a CGEA não foi fortalecida para poder dar conta de uma proposta com envergadura, daí a dificuldade para você encontrar dados".

\footnotetext{
${ }^{6}$ Cf. entrevista realizada em 16/02/2016.

Revbea, São Paulo, V. 11, № 4: 42-59, 2016.
}

revista brasileira educação ambiental 
O apoio e participação de especialistas nas consultas públicas e redação do programa viabilizaram um texto muito embasado e com boas perspectivas. Porém, como aponta Guimarães (2004), para resultar em uma ação diferenciada é necessária a práxis. Esta que não se acompanhou de forma a analisar e poder corrigir falhas ou potencializar as ações positivas.

Trajber e Moreira (2016) são enfáticas ao apontar que o Programa é muito bom, com grande chance de dar certo, elaborado em várias mãos, articulado e pensado. Moreira ainda ressalta que:

[...] o PNES surgiu de um clamor por inovação nas escolas. Surge no âmbito da educação integral - e não de tempo integral, como se tornou o Mais Educação. Mas de uma ideia de forte ligação com a comunidade, calcada na ideia de aprender fazendo e refletindo sobre o realizado, tornando a escola a incubadora de mudanças preconizadas pela transição para a sustentabilidade (MOREIRA, 2016) ${ }^{7}$.

Tanto Trajber quanto Moreira, destacam a importância do processo de formação para uma boa aplicabilidade do Programa e dos recursos. Trajber atribui à sua insistência a inclusão da prioridade de formação na primeira distribuição de recursos e cita "Porque não adianta lançar um Programa desse tipo, no PAA, o Plano de Ações Articuladas, do Ministério, sem ter uma formação com os professores".

De fato, o preparo dos profissionais contribuiria para uma melhor aplicabilidade dos recursos, bem como um maior engajamento no projeto.

Moreira considera que o processo formativo do PNES também teve ótimos resultados, com boa adesão, comprometimento e divulgação do programa. Ambas também criticam o fato de ter havido mudança no critério sem avaliação. Trajber enfatiza que "não houve avaliação posterior. Esses processos pecam muito pela falta de continuidade e de avaliação".

Sem avaliação de cumprimento dos objetivos, potencialidades e fragilidades não se torna viável qualquer modificação e melhoria, tampouco uma análise profunda da adequabilidade do volume de recursos para as implementações necessárias.

Este artigo trouxe algumas reflexões sobre a proposta do Programa Nacional Escolas Sustentáveis buscando contextualizar o conceito de Escolas Sustentáveis e Espaços Educadores Sustentáveis articulando com o processo de formação de educadores ambientais. Com a temática ambiental em alta e a crise civilizatória em curso, a EA emerge como um dos caminhos para fomentar a discussão nas escolas, visando transformar os paradigmas acerca do tratamento de temática tão essencial.

${ }^{7}$ Cf. entrevista realizada em 16/02/2016.

Revbea, São Paulo, V. 11, № 4: 42-59, 2016. 
Passados quase duas décadas de sua criação, percebe-se que a Lei № 9795, de 27 de abril de 1999, que dispõe sobre a Política Nacional de Educação Ambiental ainda carece de efetividade, dado que a consolidação da EA nas escolas requer muito mais do que sua menção em ambientes institucionalizados.

O Programa Nacional Escolas Sustentáveis tem como um dos seus pontos fortes o processo formativo continuado. Destaca-se que, a cada escola onde o curso foi disponibilizado, foram envolvidos não apenas docentes relacionados à temática, como também estudantes, funcionários e comunidade, - que corrobora as prerrogativas da EA como interdisciplinaridade e transversalidade.

A ideia de transformar a consciência em relação ao meio ambiente partindo das escolas, segundo o conceito de Escolas Sustentáveis, tem fundamento, afinal o ambiente escolar deve ser um promotor das mudanças necessárias que possibilite a criação do espaço educador sustentável, envolvendo a comunidade e levando a prática para fora dos muros do ambiente escolar.

Tendo por pressuposto este argumento, o Programa se apresenta como inovador, pois, segundo Trajber, não existem políticas públicas sobre esse tema com essa abertura.

A análise demonstrou que o objetivo do Programa Escolas Sustentáveis pode ser alcançado com apoio do processo formativo com ênfase em provocar mudanças concomitantes na gestão, na infraestrutura e nas culturas da comunidade escolar das instituições envolvidas possibilitando aprendizagens e ações resultantes de processos reflexivos sobre e na realidade escolar fundamentados na sustentabilidade ambiental.

Como sugestão de melhorias, fica o fomento dos cursos de formação de forma a abranger além de professores, membros da gestão escolar e comunidade, bem como dos órgãos públicos responsáveis pelo acompanhamento e avaliação, além dos coletivos, engajados inicialmente, mas que não têm cobrado a continuidade do Programa, de forma que, mesmo com a alternância de gestão, se consolide como uma política pública capaz de promover a transformação que se tinha como objetivo.

\section{Referências}

BRASIL. Lei 9.795, de 27 de abril de 1999. Dispõe sobre a Política Nacional de Educação Ambiental, e dá outras providencias. DOU 20.04.1999.

BRASIL. Programa Nacional de Educação Ambiental - ProNEA: documento básico. Ministério do Meio Ambiente, Diretoria de Educação Ambiental; Ministério da Educação, Coordenação Geral de Educação Ambiental. 3.ed. Brasília, 2005. 
BRASIL. Programa Nacional de Mudança do Clima. Brasília, 2008.

BRASIL. Edital no 06 SECAD/MEC, de $1^{\circ}$ de abril de 2009.Ministério de Educação. Brasília, 2009.

BRASIL. Processo Formativo em Educação Ambiental Escolas Sustentáveis e COM VIDA. Ministério da Educação. Brasília, 2010.

BRASIL. Decreto no 7.083, de 27 de janeiro de 2010. Dispõe sobre o programa mais educação. Diário Oficial da União, Brasília, 27 jan. 2010.

BRASIL. Ministério da Educação, Secretaria de Educação Continuada, alfabetização, Diversidade e Inclusão, Ministério do Meio Ambiente. Vamos cuidar do Brasil com escolas sustentáveis: educando - nos para pensar e agir em tempos de mudanças socioambientais globais. Brasília: 2012.

BRASIL. Manual Escolas Sustentáveis. Ministério da Educação. Brasília, 2013.

BRASIL. Versão preliminar do Programa Nacional de Escolas Sustentáveis. Ministério da Educação. Brasília, 2014.

DIAS, G.F.; Educação ambiental: princípios e práticas. 9. ed. São Paulo: Gaia, 2004.

GROHE, S. Escolas Sustentáveis como proposta de política pública no Brasil. Anais da X ANPED SUL, Florianópolis, outubro de 2014.

GUIMARÃES, M. Educadores ambientais em uma perspectiva crítica: reflexões em Xerém. 2003. 168 p. Tese (Doutorado em Ciências Sociais) - Instituto de Ciências Humanas, Universidade Federal Rural do Rio de Janeiro, Rio de Janeiro, 2003.

GUIMARÃES, M. A formação de educadores ambientais. Campinas: Papirus, 2004.

KASSIADOU, A.; SÁNCHEZ, C. Escolas sustentáveis e conflitos socioambientais: reflexões sobre projetos de Educação Ambiental no contexto escolar em três municípios do Estado do Rio de Janeiro. Revista VITAS Visões Transdisciplinares sobre Ambiente e Sociedade www.uff.br/revistavitas, Ano IV, № 8, 2014.

MACHADO, J.T. Um estudo diagnóstico da Educação Ambiental nas Escolas do Ensino Fundamental do Município de Piracicaba/SP. Dissertação (Mestrado em Ecologia de Agroecossistemas) - Ecologia de Agroecossistemas, Universidade de São Paulo, Piracicaba, 2008. Disponível em: $<$ http://www.teses.usp.br/teses/disponiveis/91/91131/tde-07032008-160949/>. Acesso em: 2015-03-02.

MACHADO, J.T. Educação Ambiental: um estudo sobre a ambientalização do cotidiano escolar. 2014. Tese (Doutorado em Ecologia Aplicada) - Ecologia de Agroecossistemas, Universidade de São Paulo, Piracicaba, 2014. Disponível em: $\quad<$ http://www.teses.usp.br/teses/disponiveis/91/91131/tde-07072014114108/>. Acesso em: 2015-03-02.

Revbea, São Paulo, V. 11, № 4: 42-59, 2016. 
MENEZES, A. K. Escolas sustentáveis e conflitos socioambientais: reflexões sobre o programa governamental das Escolas Sustentáveis sob a ótica da Justiça Ambiental. 2015.160 f. Dissertação (Mestrado em Educação) Universidade Federal do Estado do Rio de Janeiro, Rio de Janeiro, 2015.

MINISTÉRIO DO MEIO AMBIENTE. Agenda 21. Disponível em: $<$ http://www.mma.gov.br/component/k2/item/569?ltemid=670>. Acesso em: 2014-12-15.

MOREIRA, T.; Espaços Educadores Sustentáveis: Salto para o futuro. Ano XXI - Boletim 7. Tv. Escola, Brasília, 2011.

PEREIRA, D.M. MENDONÇA, R., SOUZA, G.V., ZANON, A.M. Processo de formação de professores por intermédio do ensino a distância para promoção de transformações socioambientais: processo formativo escolas sustentáveis e Com-Vida. Anais do ESUD 2011 - VIII Congresso Brasileiro de Ensino Superior a Distância Ouro Preto, outubro de 2011 - UNIREDE.

SANTOS, R.S.S. A formação de professores em Educação Ambiental: processos de transição para a Sustentabilidade. Anais do XVI ENDIPE Encontro Nacional de Didática e Práticas de Ensino - UNICAMP - Campinas 2012. Junqueira\&Marin Editores Livro 2 - p.000750

SATO, M.; CARVALHO, I. (Orgs.); Educação Ambiental, Pesquisas e Desafios. Porto Alegre. Artmed, 2005.

SILVA, K. A formação de professores na perspectiva crítico-emancipadora. Linhas Críticas: Revista da Faculdade de Educação. Universidade de Brasília: Brasília: FE/UNB, 2011.

SORRENTINO, M. et al. Educação ambiental como política pública. Educação e Pesquisa, São Paulo, v. 31, n. 2, p. 285-299, maio-ago. 2005.

SOTERO, J.P.; SORRENTINO, M.; A Educação Ambiental como política Pública: Reflexões sobre seu financiamento. Anais do V encontro da ANPPAS. Florianópolis, SC. 2010.2 GT-6. Disponívelem:<http://www.anppas.org.br/encontro5/cd/artigos/GT6-69-14120100824093859.pdf>. Acesso em 14 de janeiro de 2016.

TRAJBER, R.; SATO, M. Escolas sustentáveis: incubadoras de transformações nas comunidades. Revista Eletrônica do Mestrado em Educação Ambiental, v. especial, p. 70 - 78, 2010.

WIZIACK, S.R.C.; VARGAS, I.A.; ZANON, A.M. Programa Escolas Sustentáveis: reflexões para a formação de educadores ambientais no Brasil Anais do VII EPEA - Encontro Pesquisa em Educação Ambiental Rio Claro SP, 07 a 10 de Julho de 2013.

WIZIACK, S.R.C. Subsídios para a inserção da Educação Ambiental no projeto pedagógico escolar. In: VARGAS, I.A. (Org.) Gotas de saber: reflexão e prática. Campo Grande, MS, ED. Oeste, 2006.

Revbea, São Paulo, V. 11, № 4: 42-59, 2016.

revista brasileira

educação ambiental 